\title{
Stabilisotopenverdünnungsanalysen zur Quantifizierung organischer Spurenkomponenten in der Lebensmittelanalytik
}

\author{
Michael Rychlik $\cdot$ Stefan Asam
}

Erhalten: 23. September 2008/Akzeptiert: 28. Juli 2009/Online veröffentlicht: 2. September 2009

(C) Springer-Verlag 2009

Zusammenfassung Hintergrund und Ziel Das Prinzip von Stabilisotopenverdünnungsanalysen (SIVAs) und deren Anwendung in der Lebensmittelanalytik sind Themen dieses Übersichtsbeitrags. Die Grundlage dieser Methode ist die Verwendung von internen Standards, die mit stabilen Isotopen markiert sind.

Schwerpunkte Ausgehend von einem kurzen Rückblick auf die historische Entwicklung dieser Technik werden die chemisch-physikalischen Ursachen erläutert, weshalb durch SIVAs deutlich sicherere und präzisere Daten erhalten werden als durch klassische Analysenverfahren. Daneben werden Synthesestrategien für geeignete isotopologe Standards und verschiedene Kalibrierverfahren vorgeschlagen.

Ergebnisse Die vollständige Kompensierung nicht nur von Analytverlusten während der Probenaufreinigung, sondern auch der Ionensuppression bei Anwendung von LCESI-MS und der sogenannte Carrier Effekt sind wesentliche Vorzüge von Stabilisotopenverdünnungsanalysen. Allerdings können eine unzureichende Äquilibrierung zwischen Standard und Analyt bei der Probenvorbereitung und vor allem spektrale Überlappungen und Isotopeneffekte zu fehlerhaften Ergebnissen führen.

Diskussion Mit ihrer Überlegenheit hinsichtlich Spezifität und Wiederfindung hat sich die Stabilisotopenverdünnungsanalyse als Referenzmethode in der klinischen Chemie

Verantwortlicher Herausgeber: Hubertus Brunn

M. Rychlik $(\bowtie)$

BIOANALYTIK Weihenstephan, Zentralinstitut für Ernährungsund Lebensmittelforschung (ZIEL), Technische Universität München, Alte Akademie 10, 85350 Freising, Deutschland

E-Mail: michael.rychlik@wzw.tum.de

S. Asam

Lehrstuhl für Lebensmittelchemie der Technischen Universität München, Lichtenbergstr. 4, 85748 Garching, Deutschland durchgesetzt. In der Lebensmittelanalytik wird die Methode inzwischen häufig in der Aroma- und Pestizidanalytik angewendet, gewinnt aber auch in der Analyse von Mykotoxinen, weiteren Kontaminanten und Vitaminen an Bedeutung.

Schlussfolgerungen Mit der zunehmenden kommerziellen Verfügbarkeit von isotopologen Standards bzw. der Entwicklung einfacher Synthesewege werden laufend neue Anwendungen für die SIVA erschlossen.

Ausblick Die Akzeptanz der Methode vor allem im Bereich der Anwender der LC-MS spiegelt sich in der wachsenden Zahl von Einsatzbereichen auch in der Lebensmittelanalytik wieder. Weitere Anwendungsgebiete, v. a. für physiologisch oder toxikologisch hochaktive Verbindungen, werden laufend entwickelt.

Schlüsselwörter Isotopologe $\cdot$ LC-MS/MS ·

Lebensmittelanalytik · Mykotoxine ·

Stabilisotopenverdünnungsanalyse (SIVA) $\cdot$ Vitamine

\section{Stable isotope dilution assays for quantitation of organic trace compounds in food analysis}

Abstract Background and scope The principle and applications of stable isotope dilution assays (SIDAs) in food analysis is critically reviewed. This method is based on the application of internal standards labelled with stable isotopes.

General topics The general section includes historical aspects of SIDAs, the prerequisites and limitations of the use of stable isotopically labelled internal standards along with possible calibrations procedures. The syntheses and availability of labelled food compounds for the use as internal standards is reviewed.

Results The complete compensation for losses of analytes during clean-up as well as for ion suppression during 
LC-MS/MS and the so-called carrier effect are major advantages of SIDAs. However, deficient equilibration, spectral overlap and isotope effects can lead to false results.

Discussion With regard to specificity and recovery, SIDAs generally are considered as the reference methods in clinical chemistry. In food chemistry, this method has been applied in flavour and pesticide analysis. However, it is becoming increasingly important also in the analysis of mycotoxins, further contaminants and vitamins.

Conclusions The increasing access to isotopologic standards creates continuously new applications for SIDAs, particularly for bioactive compounds in foods.

Keywords Food - Isotopologues · LC-MS/MS · Mycotoxins $\cdot$ Stable isotope dilution assay (SIDA) . Vitamins

\section{Grundlagen der Stabilisotopenverdünnungsanalyse}

\subsection{Geschichtliches}

Die Wurzeln der Isotopenverdünnungsanalyse (IVA) reichen zurück in die ersten Jahrzehnte des 20. Jahrhunderts. Im Jahre 1913 wurde Georg von Hevesy von Ernest Rutherford beauftragt, so genanntes Radium D, das vierte Folgeprodukt des radioaktiven Zerfalls von Radium, vom Endprodukt dieser Zerfallsreihe, dem Radium G, zu trennen. Trotz großer Bemühungen waren alle Versuche zum Scheitern verurteilt, da sich die beiden Komponenten chemisch zu wenig voneinander unterschieden (Paneth und Hevesy 1914). Wie sich einige Jahre später herausstellte, handelte es sich bei beiden Komponenten um Blei, die eine Atomsorte war jedoch radioaktiv, die andere stabil. Sie wiesen zwar dieselbe Kernladung auf, besaßen aber verschiedene Atommassen. Da das radioaktive Blei von stabilem Blei nicht zu trennen war, erkannte von Hevesy, dass man radioaktives Blei dazu verwenden konnte, um das Verhalten dieses Elements während chemischer und physikalischer Prozesse zu verfolgen. Weil sich Radioaktivität sehr empfindlich detektieren lässt, konnte er somit z.B. das Löslichkeitsprodukt von mit „Radium D“ markierten Bleisalzen durch Messung der Radioaktivität der Lösung bestimmen (Hevesy und Paneth 1913). Diese Beobachtung führte in den Jahren zwischen 1909 und 1913 zum Postulat vom Vorkommen der Elemente in verschiedenen Nuklidarten, den sogenannten „Isotopen“ (Soddy 1913). Der Beweis für deren Existenz wurde kurz darauf durch die ersten Massenspektrometer (Aston 1919) erbracht. Inzwischen sind von den meisten Elementen stabile und radioaktive Isotope bekannt. So besteht zum Beispiel natürlicher Kohlenstoff aus ${ }^{12} \mathrm{C}(98 \%),{ }^{13} \mathrm{C}(1,1 \%)$ und radioaktivem ${ }^{14} \mathrm{C}$ (Tabelle 1).
Tabelle 1 Häufigkeit der natürlich vorkommenden stabilen Isotope ausgewählter Elemente

\begin{tabular}{lcc}
\hline Element & Isotop & Natürliche Häufigkeit \\
\hline Kohlenstoff & ${ }^{12} \mathrm{C}$ & $98,89 \%$ \\
& ${ }^{13} \mathrm{C}$ & $1,11 \%$ \\
Stickstoff & ${ }^{14} \mathrm{~N}$ & $99,634 \%$ \\
& ${ }^{15} \mathrm{~N}$ & $0,366 \%$ \\
Sauerstoff & ${ }^{16} \mathrm{O}$ & $99,762 \%$ \\
& ${ }^{17} \mathrm{O}$ & $0,038 \%$ \\
& ${ }^{18} \mathrm{O}$ & $0,200 \%$ \\
Silicium & ${ }^{28} \mathrm{Si}$ & $92,23 \%$ \\
& ${ }^{29} \mathrm{Si}$ & $4,67 \%$ \\
& ${ }^{30} \mathrm{Si}$ & $3,10 \%$ \\
Schwefel & ${ }^{32} \mathrm{~S}$ & $95,02 \%$ \\
& ${ }^{33} \mathrm{~S}$ & $0,75 \%$ \\
& ${ }^{34} \mathrm{~S}$ & $4,21 \%$ \\
& ${ }^{35} \mathrm{~S}$ & $0,02 \%$ \\
\hline
\end{tabular}

Seit der Erfindung des Massenspektrometers war man bei der IVA nicht mehr auf die Verwendung von mit radioaktiven Isotopen markierten Verbindungen angewiesen. Dadurch wurde die Anwendung der IVA um einiges unkomplizierter, da kein Strahlenschutz mehr erforderlich war. Mit dem Einsatz von stabilen Isotopen zur Markierung wird das Verfahren somit als Stabilisotopenverdünnungsanalyse (SIVA) bezeichnet. Hevesy setzte als erster mit schwerem Wasser $\left({ }^{2} \mathrm{H}_{2} \mathrm{O}\right)$ eine stabilisotopenmarkierte Verbindung zur Bestimmung des Volumens der extrazellulären Flüssigkeit ein (Hevesy und Jacobsen 1940). Was heutzutage bei diesen Versuchen kurios anmutet, ist, dass das Isotopologenverhältnis von ${ }^{2} \mathrm{H}_{2} \mathrm{O}$ zu ${ }^{1} \mathrm{H}_{2} \mathrm{O}$ durch Dichtemessung erfolgte, da die zu dieser Zeit entwickelten Massenspektrometer eine schlechtere Genauigkeit aufwiesen.

Obwohl sie sich in ihren Eigenschaften sehr ähneln, können Isotope aufgrund ihrer unterschiedlichen Massen ab- oder angereichert werden, was zu Verschiebungen des natürlichen Isotopenverhältnisses führt. Wenn ein Element mit einer natürlichen Isotopenverteilung mit einem solchen isotopisch veränderten Material gemischt wird (Abb. 1), werden die natürlich enthaltenen Isotope im resultierenden Material verdünnt. Daraus resultiert die Bezeichnung „Verdünnung" in dem für die Methode verwendeten Begriff Stabilisotopenverdünnungsanalyse. In der Literatur wird der Name „Isotopenverdünnungsanalyse“ zuerst von Rittenberg und Foster (1940) genannt, die stabilisotopenmarkierte Verbindungen zur Quantifizierung von Aminosäuren und Fettsäuren einsetzten.

Das Vorgehen bei einer SIVA war lange Zeit recht mühsam, da die zu bestimmenden Substanzen vor der Detektion durch Massenspektrometrie (MS) mit den damals verfügbaren Trennmethoden wie Kristallisation oder Destillation gereinigt werden mussten. Erst die Entwicklung der Gas- 


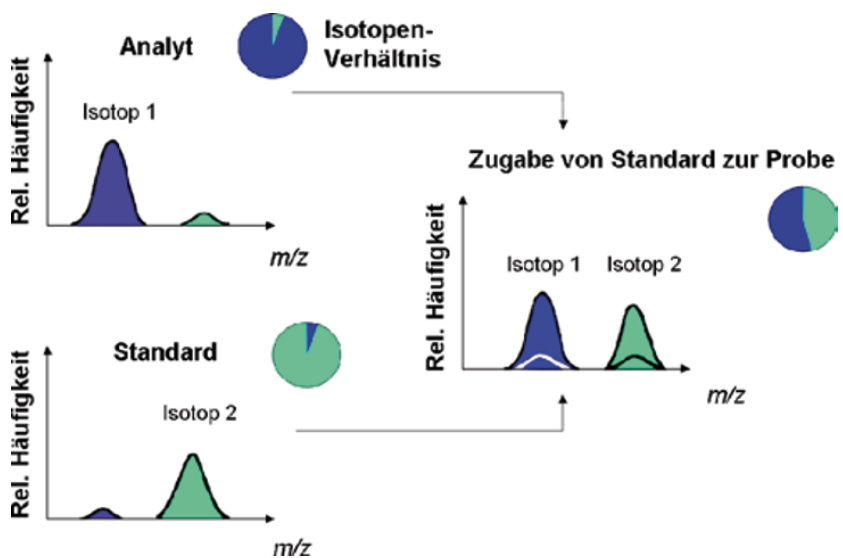

Abb. 1 Stabilisotopenverdünnungsanalyse: Die Zugabe eines Standards mit anderer Isotopenverteilung führt zur „Verdünnung“ der natürlichen Isotopenverteilung

chromatografie (GC) durch James und Martin sowie deren Kopplung mit der MS durch Holmes und Morell (1957) vereinfachte das Vorgehen erheblich. Die erste „moderne“ SIVA kann schließlich Sweeley et al. (1966) zugeschrieben werden, die Glucose mit siebenfach deuterierter Glucose als internem Standard in die Trimethylsilylderivate überführten und mittels GC/MS quantifizierten.

\subsection{Prinzip der Stabilisotopenverdünnungsanalyse}

Das Prinzip der SIVA ist in Abb. 2 anschaulich dargestellt. Nach Zugabe des markierten Standards und seiner Äquilibrierung mit dem Analyten bleibt das Verhältnis der Isotopologen aufgrund ihrer annähernd identischen chemischen und physikalischen Eigenschaften unverändert. Während Probenaufreinigung und Derivatisierung weisen beide Verbindungen die gleiche Ausbeute auf. Insbesondere bei den für die Gaschromatografie notwendigen Silylierungen, die zum Teil unvollständig oder sehr variabel sein können, bietet sich diese Technik an. Erst bei der abschließenden massenspektrometrischen Bestimmung wird zwischen den Isotopologen differenziert, und mit der bekannten Menge an zugegebenem Standard kann schließlich der Gehalt des Analyten in der Probe berechnet werden. Aufgrund der identischen Eigenschaften kann man zudem unabhängig von auftretenden Störungen durch Matrixkomponenten die gleiche Ionenausbeute für Analyt und Standard im Massenspektrometer erwarten. Im Gegensatz dazu kann ein strukturell unterschiedlicher interner Standard sowohl bei der Aufarbeitung, der Derivatisierung als auch bei der massenspektrometrischen Detektion diskriminiert werden, was systematische Fehler und schlechtere Präzision verursachen kann. Mit anderen Worten, die Verluste des Analyten werden aufgrund identischer Verluste des isotopologen Standards vollständig kompensiert, während ein strukturell

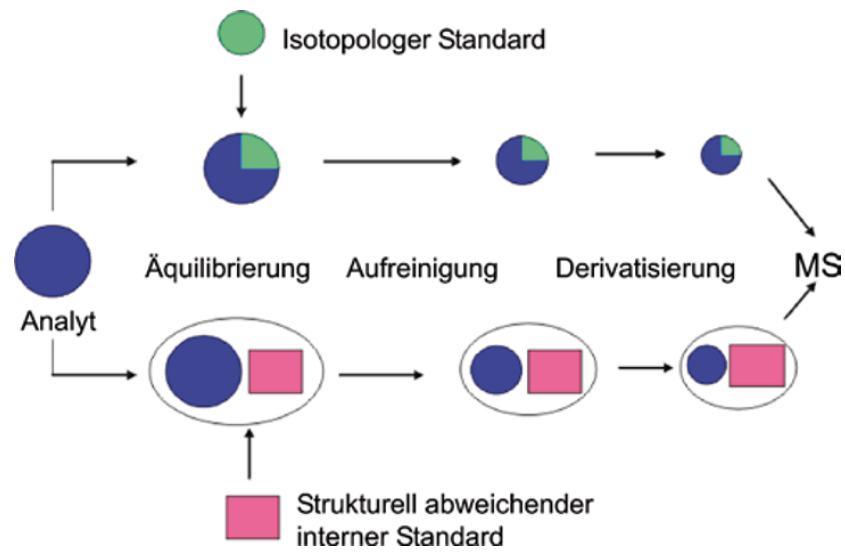

Abb. 2 Prinzip der Stabilisotopenverdünnungsanalyse: Nach Zugabe eines isotopologen Standards zum Analyten und der Äquilibrierung bleibt das Verhältnis bis zur massenspektrometrischen Analyse konstant. Beim Einsatz eines strukturell unterschiedlichen internen Standards kann sich das Verhältnis zwischen Standard und Analyt verändern und ein falsches Analysenergebnis verursachen

abweichender interner Standard unterschiedliche Verluste aufweisen kann und daher weniger geeignet ist.

\subsection{Vorteile des Einsatzes von isotopologen internen Standards}

Aufgrund der oben genannten idealen Kompensation von Verlusten werden SIVAs hauptsächlich für Analyten entwickelt, bei denen Alternativmethoden unsichere (d.h. nicht richtige) Werte ergeben. So sind dies zum einen Substanzen, die nur in Spuren vorkommen und exakter Methoden bedürfen, da mit sinkenden Konzentrationen die Messfehler überproportional zunehmen (Abb. 3). Zum anderen gehören dazu auch Verbindungen, die erst nach Reinigungsschritten erfassbar sind und während der Aufreinigung, womöglich auch aufgrund besonderer Instabilität, hohe Verluste erleiden. Beispiele für solche Verbindungen sind stark oxida-

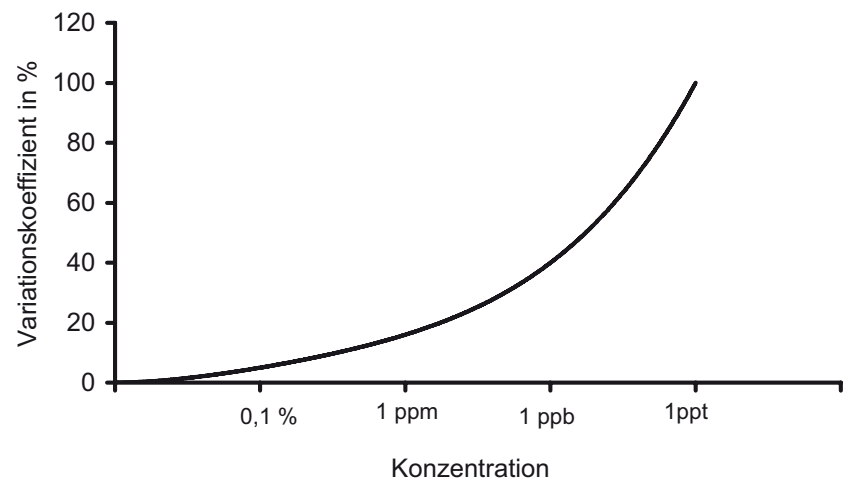

Abb. 3 Überproportionale Zunahme der Messwertstreuung mit sinkender Analytkonzentration (nach Horwitz et al. 1980) 
tionsempfindliche Substanzen wie die zu den B-Vitaminen gehörende Tetrahydrofolsäure oder der Aromastoff Methylfurfurylthiol, der darüber hinaus auch noch sehr flüchtig ist.

Beim Einsatz strukturell unterschiedlicher interner Standards oder bei externer Standardkalibrierung sind für jede Matrix Wiederfindungs- und Standardadditionsversuche notwendig, die den Arbeitsaufwand zusätzlich erhöhen. Oft sind die Wiederfindungen wenig reproduzierbar, was gleichbedeutend mit schlechter Präzision ist. Wird die Analytik mittels LC-MS durchgeführt, so beobachtet man aufgrund von störenden Matrixkomponenten in der Ionenquelle häufig eine Unterdrückung der Intensität des Signals für den Analyten, die sogenannte Ionensuppression, wodurch systematische Fehler entstehen (Jessome 2006). Da diese Interferenzen den koeluierten isotopologen Standard in gleichem Ausmaß betreffen, wird dieser Effekt bei der SIVA ebenfalls vollständig kompensiert.

Für oben genannte Analyten haben sich SIVAs in Ringversuchen als Referenzmethoden oder sogenannte „definitive" Methoden erwiesen. Daher wird der tatsächliche Gehalt in Standardreferenzmaterialien oder in Proben für Laborvergleiche oft durch SIVA bestimmt (Brown Thomas et al. 2001; Heumann 1986). In solchen Vergleichen weisen die Daten derjenigen Laboratorien, die SIVA anwenden, weit geringere Streuungen auf als diejenigen von Labors, die andere Methoden einsetzen. Dies wurde bei der Analytik von 15 Elementen (Papadakis et al. 2000) und bei organischen Verbindungen am Beispiel des Insektizids p,p'-Dichlordiphenyldichlorethen ( $\mathrm{p}, \mathrm{p}$ '-DDE) gezeigt (Webb und Carter 1997).

Ein weiterer Vorteil der SIVA ist, dass sie als sogenannte „Primäre Methode“ grundsätzlich geringe Messfehler aufweist. „Primäre Methoden“ sind jene, deren Daten sich ausschließlich aus physikalischen Grundgrößen und/oder chemischer Stöchiometrie berechnen lassen und die nicht vom empirischen Einsatz anderer chemischer Stoffe als Referenzen abhängen (Quinn 1997). Grundlegende „Primäre Methoden" sind die Coulometrie, die Gravimetrie, die Titrimetrie sowie Verfahren, die stoffmengenabhängige Eigenschaften wie die Gefrierpunkterniedrigung oder den osmotischen Druck messen. Dabei beruht die SIVA ebenfalls auf der Gravimetrie, da die Menge des zugegebenen Standards gravimetrisch bestimmt wird und analog erstellte Kalibrierkurven zwischen Analyt und isotopologem Standard den Bezug auf diese gravimetrische Messung liefern. Daher wird die SIVA auch als „Primäre Methode“ angesehen. Gravimetrische Messungen sind grundsätzlich mit geringen Fehlern behaftet und ergeben daher auch für die SIVA niedrige Standardabweichungen.

Ungeachtet der überlegenen Sicherheit der quantitativen Daten erhöht der Einsatz eines isotopologen Standards die Spezifität der Detektion. Zusätzlich zur spezifischen massenspektrometrischen Information für den Analyten zeigt der koeluierte interne Standard die entsprechenden, durch die Markierung in ihrer Masse verschobenen Signale. Daher sichert das Chromatogramm einer SIVA durch die koeluierten Peaks in den entsprechenden Massenspuren die korrekte Identifizierung des Analyten ab (Abb. 4).

Ein bisher noch nicht erwähnter Vorteil der SIVA wird als „Carrier-Effekt" bezeichnet. Dieser Effekt wirkt sich vor allem dann aus, wenn man im Standardüberschuss arbeitet, d.h. der isotopologe Standard sich nach seiner Zugabe gegenüber dem Analyten im Überschuss befindet. Dadurch wird der Analyt vom Standard durch die Analyse geschleppt und kann daher auch in geringsten Spuren noch detektiert werden. Wenn man nämlich davon ausgeht, dass bei der Probenaufreinigung immer eine gewisse absolute Menge an Substanz (markiert oder unmarkiert), z.B. durch Adsorption, verloren geht, so kann der Analyt undetektierbar
Abb. 4 Coelution von Analyt und Standard
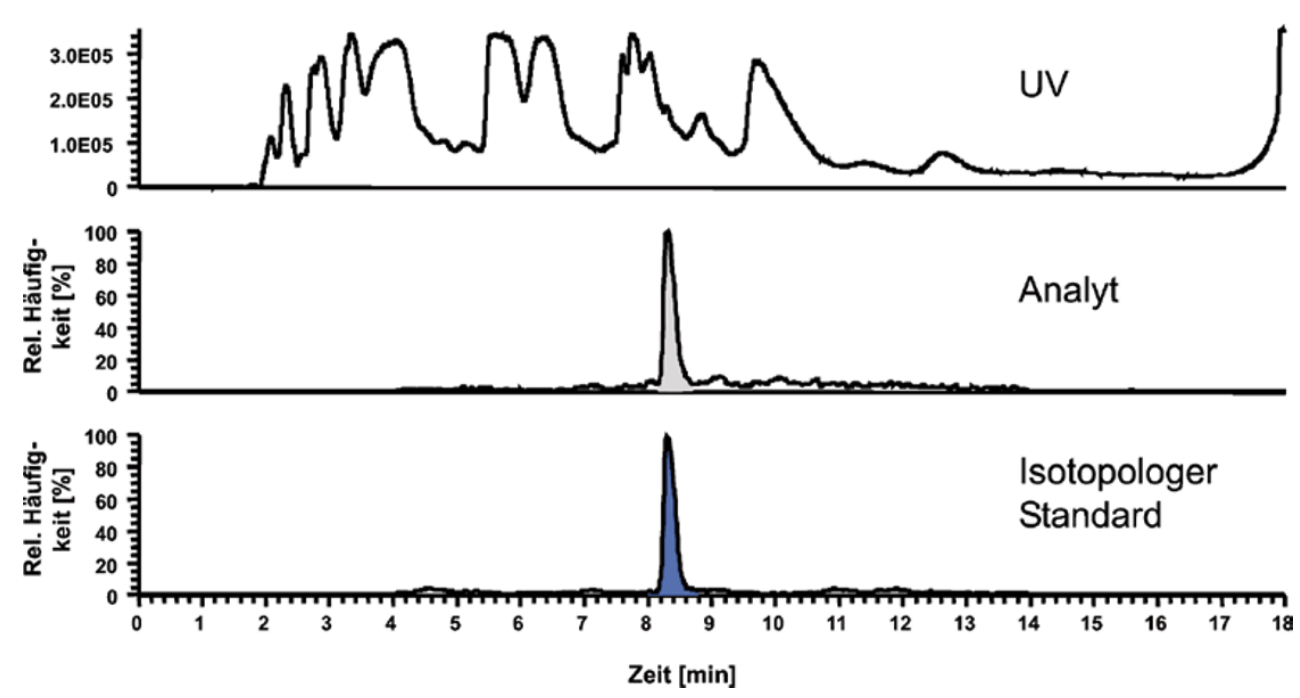
bleiben, wenn seine Menge unter diesem Niveau liegt. Wird jedoch der Gehalt an Isotopologen durch die Standardzugabe so aufgestockt, dass er über dieses Niveau steigt, können Standard und Analyt schließlich detektierbar werden. Man gewinnt daher zusätzliche Empfindlichkeit, wie am Beispiel der SIVAs einiger Arzneimittel gezeigt werden konnte (Haskins et al. 1978). Es ist jedoch zu beachten, dass man auch bei Standardüberschuss noch im auswertbaren Bereich der Kalibrierkurve arbeiten muss.

\subsection{Voraussetzung für die Richtigkeit einer SIVA}

Der Einsatz eines isotopologen internen Standards (IS) bringt eine große Verbesserung und auch Vereinfachung der Analytik mit sich, garantiert aber nur unter bestimmten Bedingungen ein richtiges Analysenergebnis.

\subsubsection{Ausreichende Äquilibrierung}

Nach Zugabe des IS muss sich die Konzentration des Analyten im richtigen Stoffmengenverhältnis der Isotopologen widerspiegeln. Dies ist nur dann der Fall, wenn sich Standard und Analyt in allen Kompartimenten der Matrix im Gleichgewicht befinden, d.h. Standard und Analyt äquilibriert sind. Da der in einem Lösungsmittel gelöste Standard entweder dem Extraktionsmittel zugesetzt oder der Matrix direkt zudotiert wird, ist anzunehmen, dass er zu einem hohen Prozentsatz während der Extraktion wieder gefunden wird. Für den Analyten mag das weniger zutreffen, da er in Kompartimente der Matrix eingeschlossen oder an Proteine bzw. andere Matrixkomponenten gebunden und damit schlechter extrahierbar sein kann. Daher muss eine ausreichende Zeit gewählt werden, um eine Äquilibrierung von Standard und Analyt in der Probe und damit ein identisches Stoffmengenverhältnis in allen Kompartimenten zu gewährleisten. Während der Dauer der Äquilibrierung besteht aber die Gefahr, dass die zu analysierende Verbindung aus endogenen Vorläufern neu gebildet wird und sich daher zu hohe Resultate für den freien Analyten ergeben. Ein häufiges Beispiel ist hier die enzymatische Freisetzung aus Glycosiden (Abb. 5), die aber z.B. durch Hitzedenaturierung des Enzyms verhindert werden kann. Ist andererseits die Bestimmung der Summe aus freiem und glycosyliertem Analyten gewünscht, bietet sich sogar die Zugabe des entsprechenden Enzyms während der Äquilibrierung an. Auf diese Weise konnte z.B. von Kotseridis et al. (1999b) der Aromastoff $\beta$-Damascenon sowohl in freier als auch in glykosidisch gebundener Form in Wein quantifiziert werden.

\subsubsection{Stabile Markierung des Standards}

Da sich das Stoffmengenverhältnis der Isotopologen während der SIVA nicht verändern darf, muss die Markierung

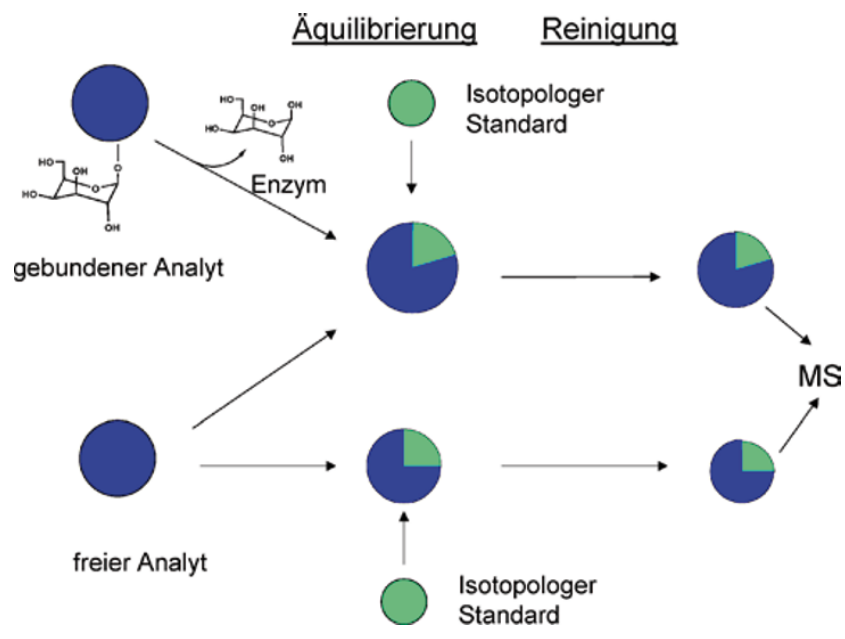

Abb. 5 Isotopenverdünnungsanalyse (IVA) nach Freisetzung des Analyten aus einem glykosylierten Vorläufer während der Äquilibrierungsphase (oberer Teil der Abb.) im Vergleich zur IVA des freien Analyten (unterer Teil der Abb.). Die obere IVA ergibt die Summe aus freiem und freigesetztem Analyten

des IS stabil sein. Der Standard darf sich während der Analyse nicht durch einen teilweisen oder kompletten Verlust der Markierung zersetzen oder sich in den Analyten umwandeln. Als wichtigste Reaktion, die eine derartige Veränderung des Standards bedingt, ist der Protium-Deuterium-Austausch zu nennen: Im Falle einer Markierung mit Deuterium muss in besonderem Maße darauf geachtet werden, dass die ${ }^{2} \mathrm{H}$-Isotope sich nicht an aciden Positionen im Molekül befinden, an denen sie gegen Protium ausgetauscht werden können. Insbesondere Deuteronen, die an Heteroatome gebunden sind, können in Säure-Base-Reaktionen durch Protonen ersetzt werden. Aber auch eine ${ }^{2} \mathrm{H}$-Markierung an aromatischen Positionen ist in Anwesenheit von starken Säuren durch elektrophile Substitution gefährdet. Dagegen sind Bindungen zwischen Kohlenstoffen oder zwischen Kohlenstoff und Stickstoff sehr schwer zu spalten, weshalb Markierungen mit $\left[{ }^{13} \mathrm{C}\right]$ oder $\left[{ }^{15} \mathrm{~N}\right]$ als sehr stabil angesehen werden. Im Gegensatz dazu ist im Falle einer Markierung mit $\left[{ }^{18} \mathrm{O}\right]$ aber ein Austausch des Sauerstoffes in Carboxylfunktionen zu beachten. Dies wurde von Boni et al. (1994) gezeigt, der den Verlust der $\left[{ }^{18} \mathrm{O}\right]-$ Markierung in Tryptophan feststellte, das in wässrigen Lösungen erhitzt wurde. Aber auch deuterierte Trimethylsilyl(TMS)-Gruppen unterliegen einem Austausch mit unmarkierten TMS-Funktionen beim Silylieren, was zum Scheitern einer SIVA im Falle des $\left[{ }^{2} \mathrm{H}\right]_{3^{-}}$ TMS-Patulins als IS führte (Price 1979).

\subsubsection{Geringe spektrale Überlappung}

Eine weitere wichtige Voraussetzung für einen isotopenmarkierten Standard ist, dass er sich massenspektrometrisch eindeutig vom unmarkierten Analogon unterscheiden lässt, 
d.h. nur ein Minimum an spektraler Überlappung mit diesem aufweist. Im Falle der eindimensionalen Massenspektrometrie ist es wichtig, dass im Massenspektrum entweder das Molekülion deutlich sichtbar oder die Markierung in einem Ion hoher Intensität erkennbar ist und nicht mit einem Neutralteilchen abgespalten wird. Vor der Synthese des internen Standards muss daher die Fragmentierung im Massenspektrometer bekannt sein bzw. durch geeignete Untersuchungen geklärt werden. Dies ist bei der TandemMassenspektrometrie von geringerer Bedeutung, da mit dieser Technik auch die Abspaltung der Markierung selektiv erfasst werden kann. Spektrale Überlappungen können aber auch auftreten, wenn natürliche Isotopologe des Analyten Ionen mit gleichen ganzzahligen Massen (sog. Isobare) wie der Standard erzeugen. Dies betrifft insbesondere die Elemente Kohlenstoff, Sauerstoff oder Silizium, deren natürliche Isotope $\left[{ }^{13} \mathrm{C}\right],\left[{ }^{18} \mathrm{O}\right]$ oder $\left[{ }^{29} \mathrm{Si}\right]$ und $\left[{ }^{30} \mathrm{Si}\right]$ besonders häufig vorkommen. Insbesondere $\left[{ }^{13} \mathrm{C}\right]$ in Verbindungen mit hoher Kohlenstoffanzahl oder $\left[{ }^{29} \mathrm{Si}\right]$ und $\left[{ }^{30} \mathrm{Si}\right]$ in für die GC silylierten Verbindungen sind dafür verantwortlich, dass in den Massenspektren dieser Verbindungen nicht nur die Nominalmassen $\mathrm{m}_{\mathrm{A}}$, sondern auch ein deutliches Auftreten von $\mathrm{m}_{\mathrm{A}}+1$ und $\mathrm{m}_{\mathrm{A}}+2$ oder sogar noch höheren Massen zu beobachten ist. Beim Arbeiten mit niedrigauflösenden Massendetektoren (Quadrupole, Ionenfallen) müssen entsprechend mehr Markierungen eingeführt werden, wenn man aufwändige Kalibrierverfahren (s. Abschn. 1.6.) zur Bestimmung des Isotopologenverhältnisses vermeiden möchte. Dabei muss aber bedacht werden, dass eine höhere Anzahl markierter Atome vor allem bei Deuterium einen deutlichen Isotopeneffekt hervorrufen kann, der die spektralen Vorteile der markierten Verbindung durch abweichende Stoffeigenschaften wieder zunichte macht (s. u.).

Spektrale Interferenzen durch natürliche Isotopologe können durch Anwendung der Tandem-Massenspektrometrie verringert werden. Ein Beispiel für diesen Ansatz ist die Quantifizierung des Mykotoxins Deoxynivalenol (DON), das von Bretz et al. (2006) durch den Einsatz von einfach deuteriertem $\left[{ }^{2} \mathrm{H}_{1}\right]$-DON bestimmt wurde. Dazu wurde im MS/MS-Modus ein Übergang gemessen, bei dem die Markierung des Standards vom Molekül abgespalten wurde. Man kann davon ausgehen, dass die durch die natürliche Isotopenhäufigkeit im Analyt eingebauten ${ }^{13} \mathrm{C}$-Isotope statistisch über alle Positionen verteilt sind. Somit ist bei einer genügend großen Anzahl von Kohlenstoffatomen die Wahrscheinlichkeit gering, dass das natürliche ${ }^{13} \mathrm{C}$, das die spektrale Überlappung verursacht, beim gleichen Massenübergang abgespalten wird, wie das bewusst an diese Stelle eingebrachte ${ }^{2} \mathrm{H}$ des markierten Standards. Auf diese Art und Weise kann der Fehler, der durch die spektrale Überlappung entsteht, verkleinert werden.

Umgekehrt können spektrale Überlappungen aber auch auftreten, wenn der Standard noch unmarkierte Substanz enthält. Dies tritt vor allem dann auf, wenn die Markierung durch unvollständige katalytische Deuterierung oder Deuterium-Protium-Austausch eingeführt oder Edukte mit ungenügender Isotopenreinheit eingesetzt wurden. Aber auch mikrobiologisch oder durch Zellkulturen hergestellte Standards enthalten oftmals noch beträchtliche Mengen der unmarkierten Zielverbindung, da Stoffwechselwege selten linear und voneinander unabhängig zu den Endprodukten führen. Stattdessen liegen vielmehr Pools vor, die von mehreren Stoffwechselquellen gespeist werden und in diverse Senken abfließen. Es lässt sich in lebenden Zellen daher kaum verhindern, dass die markierten Vorläufer im Laufe des Metabolismus mit unmarkierten Isotopologen vermischt werden.

Spektrale Überlappungen führen zwangsläufig zu nichtlinearen Beziehungen zwischen den Signalintensitätsverhältnissen und den Stoffmengenverhältnissen von Analyt und Standard, was die Auswertung zwar nicht unmöglich macht, aber unnötig erschwert. Von spektraler Überlappung unterschiedlicher Substanzen mit gleichen Molekülmassen ist der Messfehler bei Isotopensignalen aufgrund unzureichender Auflösung des Massenspektrometers zu unterscheiden. Übliche Quadrupolgeräte weisen eine Präzision der Isotopenverhältnismessung zwischen 1 und $3 \%$ auf, die abhängig von der Gesamtsignalintensität ist. Für die Messung von angereicherten Isotopologen ist das in der Regel völlig ausreichend. Sollen jedoch Unterschiede im natürlichen Isotopenverhältnis gemessen werden, wie dies mittels Isotopenverhältnismassenspektrometrie (IRMS) zum Herkunfts- und Authentizitätsnachweis geschieht, sind Messgenauigkeiten von unter $1 \%$ erforderlich. Dies erreicht man mittels Sektorfeldgeräten und Faradaykollektoren bei fest eingestellten Radien und alternierender Messung von Referenzstandards.

Beim Arbeiten mit hochauflösenden Massendetektoren (Sektorfeld-, Flugzeit- oder Orbitrapgeräten) lassen sich sogar Signale von Isobaren trennen, die eine gleiche ganzzahlige Molekülmasse bei unterschiedlicher Elementarzusammensetzung aufweisen. Während niedrigauflösende Massendetektoren diese Isobarensignale nicht unterscheiden können, sind für Geräte mit entsprechend hoher Auflösung die Signale aufgrund kleiner Massenunterschiede trennbar.

\subsubsection{Ausschluss von Isotopeneffekten}

Eine weitere Bedingung für eine korrekte IVA ist, dass das Isotopenverhältnis nicht durch Isotopeneffekte verfälscht wird. Darunter versteht man unterschiedliches chemisches oder physikalisches Verhalten von Isotopologen, das durch deren Massendifferenz hervorgerufen wird. Beispiele hierfür sind Isotopeneffekte bei chemischen Reaktionen, wie z. B. der Eliminierung von $\left[{ }^{2} \mathrm{H}\right] \mathrm{Br}$ aus deuterierten Bromalkanen (Streitwieser und Heathcock 1980) oder bei enzymatischen 


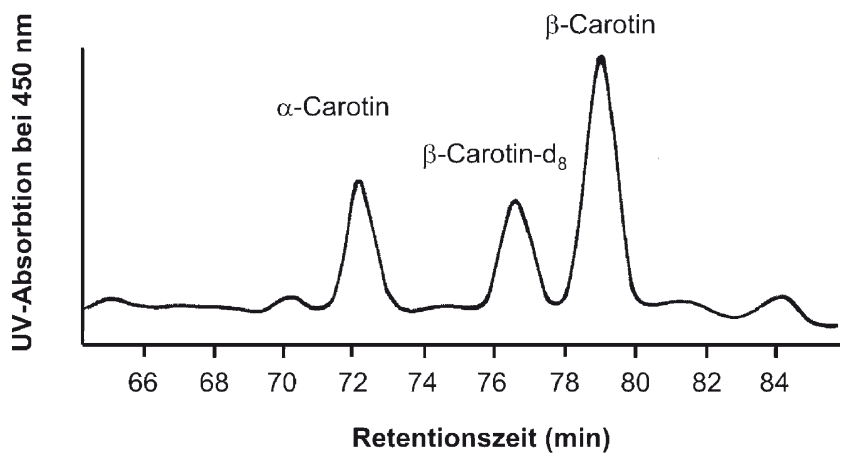

Abb. 6 Grundlinientrennung von achtfach deuteriertem $\beta$-Carotin und unmarkiertem $\beta$-Carotin durch HPLC (nach Dueker et al. 1994)

Umsetzungen. Diskriminierungen bei letzteren Reaktionen werden sogar dazu angewandt, um die Biosynthesewege von Pflanzeninhaltstoffen zu differenzieren und somit die Authentizität von Lebensmitteln zu überprüfen. Isotopeneffekte können ebenfalls bei physikalischen Trennmethoden, wie z.B. der Chromatografie, auftreten. Hier können sich die Eigenschaften der Isotopologen so weit unterscheiden, dass diese, wie im Falle von Carotin und dessen deuterierten Analoga (Abb. 6), grundliniengetrennt werden können. Im Allgemeinen machen sich Isotopeneffekte besonders im Falle von Deuterium bemerkbar, da sich dessen Massenunterschied von $100 \%$ gegenüber Protium in größerer Trägheit und geringerer Polarisierbarkeit von Bindungen auswirkt. Es ist daher einleuchtend, dass eine mehrfache Markierung mit Deuterium sorgfältig bedacht werden muss, um nicht durch merkliche Isotopeneffekte das Isotopologenverhältnis zu verschieben und somit die Richtigkeit der Analyse zu gefährden. Markierungen mit $\left[{ }^{13} \mathrm{C}\right]$ oder $\left[{ }^{15} \mathrm{~N}\right]$ äußern sich dagegen in viel geringeren Isotopeneffekten und sind deshalb einer Markierung mit Deuterium vorzuziehen.

\subsection{Synthesen von isotopologen Standards}

Das größte Hindernis für die Entwicklung einer SIVA ist die Verfügbarkeit des IS, da die wenigsten Standards kommerziell erhältlich sind. Dagegen sind aber für eine Vielzahl von markierten Verbindungen Synthesewege publiziert. Auch wenn die Kosten für die markierten Edukte sinken und der Syntheseaufwand der Standards laufend optimiert wird, stellt die synthetische Arbeit für die Anwender oft ein psychologisches Hindernis dar. Dabei bestehen die Vorschriften oft aus weniger als zehn synthetischen Stufen und sind zumeist gut nachvollziehbar. Ein weiteres psychologisches Hindernis ist der Preis der markierten Edukte. Das ist jedoch kein zwingendes Argument, was an folgendem Beispiel erläutert werden kann: Ein Gramm des markierten Eduktes mag um die $1000 €$ kosten und die Ausbeute der Synthese $10 \%$ betragen, was beides realistische Annahmen sind. Folglich wird der Preis für $100 \mathrm{mg}$ markierten Produktes ebenfalls $1000 €$ betragen. Da für eine SIVA nur 1 bis $10 \mu \mathrm{g}$ des markierten Standards erforderlich sind, ermöglichen $100 \mathrm{mg}$ des Standards mindestens 10.000 Analysen. Folglich werden die Materialkosten für den Standard in etwa $0,10 €$ je Probe betragen, was gegenüber den Kosten für Personal und Ausrüstung vernachlässigbar ist.

Sollte der Syntheseweg bisher nicht publiziert sein, so ist man gezwungen, eine eigene Route zu entwickeln. Dabei ist eine Strategie mit möglichst wenigen Zwischenstufen zu wählen. Ein Beispiel für dieses Vorgehen ist die Deuterierung des Isoflavons Daidzein durch direkten $\mathrm{BF}_{3}$-katalysierten H-D-Austausch (Abb. 7) nach Rasku et al. (1999). Diese Markierung ist jedoch nur stabil, weil stark saure Bedingungen während der Analyse nicht auftreten. Für viele Analyten ist es jedoch notwenig, stabile ${ }^{13} \mathrm{C}$ - oder ${ }^{15} \mathrm{~N}$-Markierungen einzubringen, wozu oft mehrstufige Synthesen erforderlich sind, die mit mehr oder minder guten Ausbeuten einhergehen. Da die isotopenmarkierten Vorstufen meist den größten Kostenfaktor darstellen, sind diejenigen Wege zu bevorzugen, bei denen die Markierung erst in den letzten Stufen eingeführt wird, um Verluste von markierten Verbindungen zu minimieren. So kann ein solcher Syntheseweg, der möglicherweise schlechtere Gesamtausbeuten aufweist, einem Alternativweg vorzuziehen sein, der zwar höhere Ausbeuten verspricht, bei dem die Markierung aber früher eingebaut werden muss und daher weniger markierte Endverbindung bei gleichen Kosten erzeugt (Abb. 8).

Bei der Auswahl der Synthesestrategie ist ebenfalls zu prüfen, ob für optisch aktive Zielverbindungen ein stereoselektiver Weg notwendig ist. Dies ist vor allem dann von Bedeutung, wenn während der Analyse enantiomere Umgebungen auftreten und von einem racemischen Standard ein
Abb. 7 Deuterierung des Isoflavons Daidzein (nach Rasku et al. 1999)

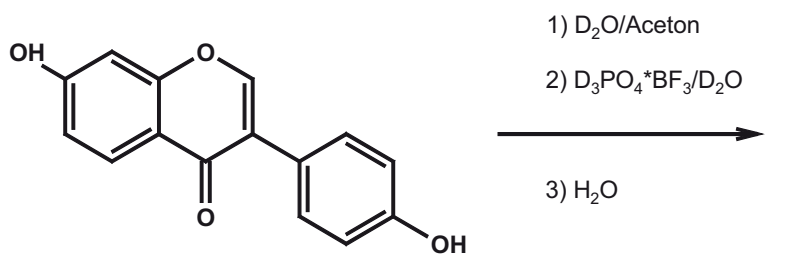<smiles>[2H]c1cc(-c2coc3c([2H])c(O)ccc3c2=O)cc([2H])c1O</smiles> 


\begin{tabular}{|c|c|c|c|c|c|}
\hline \multirow[t]{3}{*}{ Weg $A$} & \multicolumn{5}{|c|}{ 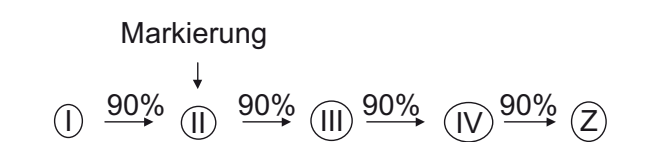 } \\
\hline & GA & $90 \%$ & $81 \%$ & $73 \%$ & $65 \%$ \\
\hline & AM & $100 \%$ & $91 \%$ & $81 \%$ & $73 \%$ \\
\hline \multirow[t]{3}{*}{ Weg B } & \multicolumn{5}{|c|}{\begin{tabular}{c}
\multicolumn{2}{c}{ Markierung } \\
(1) $\stackrel{80 \%}{\longrightarrow}$ (2) $\stackrel{80 \%}{\longrightarrow}$ (3) $\stackrel{80 \%}{\longrightarrow} \stackrel{80 \%}{\longrightarrow}$ (2)
\end{tabular}} \\
\hline & GA & $80 \%$ & $64 \%$ & $51 \%$ & $41 \%$ \\
\hline & $A M$ & & & $100^{\circ}$ & $80 \%$ \\
\hline
\end{tabular}

Abb. 8 Vergleich der Gesamtausbeute (GA) sowie der Ausbeute an markiertem Material (AM) zweier Synthesewege zum Zielmolekül Z. Weg A ergibt trotz höherer GA eine niedrigere AM als Weg B, da bei letzterem die Markierung in einem späteren Syntheseschritt eingebaut wurde

Enantiomeres diskriminiert würde. Dieser Effekt spielt vor allem bei der Immunoaffinitätschromatografie eine Rolle, die in der Spurenanalytik immer mehr Verbreitung findet.

Neben dem synthetischen Aufwand sind die Kosten der isotopenmarkierten Vorstufen zu berücksichtigen. Deuterierte Verbindungen sind in der Regel am kostengünstigsten wegen ihrer leichten Herstellungsmöglichkeit sowie ihres häufigen Einsatzes als Lösungsmittel bei der NMR-Spektroskopie. Demgegenüber sind die oben genannten Nachteile der deuterierten Substanzen in Bezug auf die Isotopeneffekte abzuwägen. Aber auch die Preise für ${ }^{13} \mathrm{C}$ - oder ${ }^{15} \mathrm{~N}$-Verbindungen sind in letzter Zeit deutlich zurückgegangen, seitdem die Kapazitäten für die Gewinnung von ${ }^{13} \mathrm{CO}_{2}$ sowie ${ }^{15} \mathrm{NH}_{3}$ durch Ultrazentrifugen sowie die Synthesekapazität für die darauf basierenden Folgeprodukte zugenommen haben. Inzwischen sind die meisten Aminosäuren, viele
Monosaccharide und Grundchemikalien sowohl deuteriert als auch mit ${ }^{13} \mathrm{C}$ markiert kommerziell erhältlich.

\subsection{Kalibrierungsverfahren}

Wie bei allen Verfahren, die sich eines internen Standards bedienen, erfolgt die Berechnung des Analytgehalts auch bei der SIVA über eine Kalibrierfunktion. Diese beschreibt die Beziehung zwischen dem durch Massenspektrometrie ermittelten Ionenintensitätsverhältnis und dem Stoffmengenverhältnis der Isotopologen. Analytisch wird diese Beziehung durch die Messung von Standard-Analyt-Mischungen in verschiedenen Verhältnissen gewonnen. Im idealen Fall ergibt sich für die Kalibrierfunktion eine Nullpunktgerade mit der Steigung 1. In der Praxis weisen die Funktionen aufgrund von spektraler Überlappung aber Abweichungen vor allem im Standardunterschuss und -überschuss auf. In Abb. 9 ist eine Kalibrierfunktion für den realistischen Fall berechnet, dass der Standard 2\% unmarkierte Substanz enthält und natürliche Isotopologe des Analyten, die ein dem Standard analoges Signal ergeben, 5\% der Analytmenge betragen.

Im Standardüberschuss (d.h. bei Stoffmengenverhältnissen von Standard zu Analyt über 10:1) sind es die Anteile an unmarkiertem Standard und im Standardunterschuss (d.h. bei Stoffmengenverhältnissen von Standard zu Analyt unter 1:10) die natürlichen Isotopomere des Analyten, die Abweichungen von der Linearität ergeben. Im gezeigten Falle ist es empfehlenswert, den Bereich der auswertbaren Ionenintensitätsverhältnisse so einzuschränken, dass die Abweichungen von der Linearität die Güte des Ergebnisses nicht wesentlich verschlechtern. Im vorliegenden Falle wäre ein auswertbarer Bereich in einem Standard-Analyt-Verhältnis zwischen 0,2 und 5 zu empfehlen.

In manchen Fällen ist jedoch eine Auswertung im nichtlinearen Bereich unumgänglich. Dies ist dann gegeben, wenn bei der Synthese höhere Gehalte an unmarkierter Substanz
Abb. 9 Kalibrierfunktion für eine Isotopenverdünnungsanalyse, bei der der Standard 2\% unmarkierte Substanz enthält und natürliche Isotopologe des Analyten, die ein dem Standard analoges Signal ergeben, $5 \%$ der Analytmenge betragen

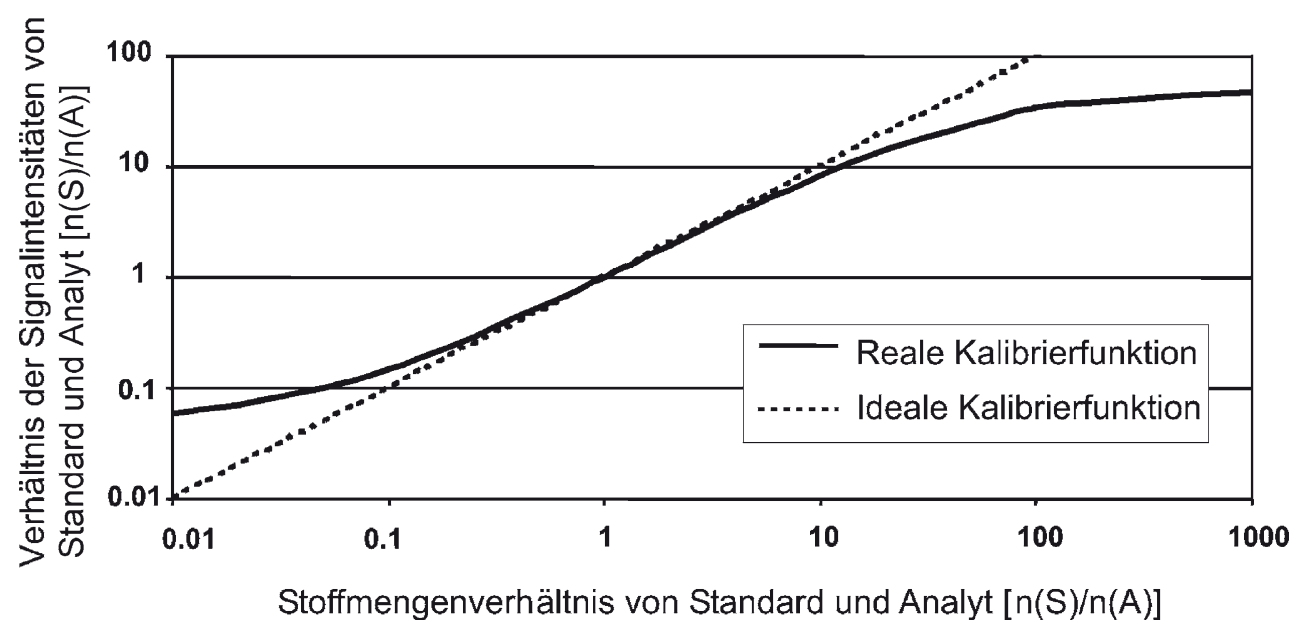


entstanden sind oder nicht genügend Markierungen eingebaut werden konnten. Auch ist es denkbar, dass wegen zu niedriger Analytkonzentrationen im hohen Standardüberschuss gearbeitet werden muss, um den „Carrier-Effekt“ (s. o.) auszunützen. Für diese Gelegenheiten wurden Näherungsverfahren entwickelt, die die Kalibrierfunktion unter Berücksichtigung oben genannter Ursachen für spektrale Überlappungen berechnen (Sabot et al. 1988) oder durch polynomische bzw. hyperbolische Regression aus vorhandenen Kalibrierpunkten annähern (Jonckheere et al. 1983). Da diese Verfahren ziemlich aufwändig sind, schlugen verschiedene Autoren Linearisierungsmethoden vor, die die nichtlineare Funktion in eine lineare überführen. Kürzlich verglichen Fay et al. (2001) vier dieser Methoden beim Einsatz von $\left[{ }^{2} \mathrm{H}_{1}\right]$-Benzaldehyd als IS für die Quantifizierung von Benzaldehyd. Diese Markierung ergibt eine spektrale Überlappung von $12 \%$. Die Autoren konnten zeigen, dass die Methode von Colby und McCaman (1979) keine lineare Funktion ergab. Durch den Ansatz der mittleren Massen (Blom 1987) und der Linearisierung durch Einführung von isotopischen Anreicherungsfaktoren (Staempfli et al. 1994) konnten zwar Geraden erhalten werden, deren Kalibrierpunkte waren aber sehr inhomogen verteilt. Die einzige Methode, die eine Kalibriergerade mit homogen verteilten Kalibrierpunkten ergab, war die Methode von Bush und Trager (1981), welche bemerkenswerterweise auch nur einfache Rechnungen erforderte. Ein anderes, aber aufwändigeres Näherungsverfahren ist die sogenannte „Bracketing“-Methode (Cohen et al. 1980). Hierbei werden für das Ionenintensitätsverhältnis einer unbekannten Probe Kalibrierpunkte in geringem Abstand aufgenommen, sodass sie das Ionenintensitätsverhältnis der Probe einrahmen. Der Bereich zwischen den Kalibrierpunkten, in dem sich auch die Probe befindet, wird dabei als linear angenommen.

Neben der Kalibrierfunktion muss für die Auswertung einer SIVA die Menge an zugegebenem Standard genau bekannt sein. Im Idealfall liegt der Standard in genügender Menge und Reinheit vor, kann eingewogen und auf die passende Verdünnung gebracht werden. Leider sind die Standardlösungen selten zu $100 \%$ rein, nicht unbegrenzt stabil und können nicht vor jedem Versuch neu eingewogen werden. Dann muss ihre Konzentration mit herkömmlichen Methoden wie der UV-Spektroskopie, GC-FID oder HPLCUV bestimmt werden.

\section{Anwendungsbeispiele für SIVA in der Lebensmittelanalytik}

Die Überlegenheit der SIVA gegenüber anderen Analysetechniken führte bald dazu, dass sie sich als Referenzmethode für Analyten in der klinischen Chemie durchsetzte, bei denen sichere Daten für eine eindeutige Diagnose oder für die Bewertung der Pharmakokinetik entscheidend sind. Deshalb existieren SIVAs für die wichtigsten Arzneimittel, aber auch für Hormone oder Drogen. In die Lebensmittelanalytik wurden die für die klinische Diagnostik und Umweltanalytik entwickelten SIVAs vereinzelt übernommen und zum Beispiel zur Analytik von verschiedenen Vitaminen in Lebensmitteln verwendet (Tabelle 2).

Eine weite Verbreitung der SIVA in der Lebensmittelanalytik ist insbesondere in der Aromaanalytik gegeben, bei der die Flüchtigkeit der Analyten ein besonderes Problem darstellt, das sich durch SIVA sehr gut kompensieren lässt. Nach der erstmaligen Verwendung durch Schieberle und Grosch (1987) zur Quantifizierung von Aromastoffen in Brot wurde eine Vielzahl von weiteren SIVAs für geruchsaktive Verbindungen entwickelt, von denen nur eine Auswahl in Tabelle 2 aufgeführt werden kann. In jüngerer Zeit findet dieses Konzept auch Anwendung in der Analytik von Geschmacksstoffen (Stark et al. 2006) oder anderen Minorkomponenten in Lebensmitteln, von denen eine ernährungsphysiologische oder technologische Funktion ausgeht (Tabelle 2).

Ein klassisches Gebiet, für das sich der Einsatz von SIVA anbietet, ist die Analytik von Rückständen und Kontaminanten, die in der Regel nur in geringen Spuren in Lebensmitteln enthalten sind und eine weitestgehende Probenaufreinigung erfordern. Insbesondere seit mehr und mehr LC-MS-Methoden für diese Analyten entwickelt werden, ist die Verwendung von isotopenmarkierten internen Standards auch aus Gründen der Ionensuppression in der Ionenquelle des LC-MS-Geräts notwendig geworden. Aus diesem Bereich sind die SIVAs für verschiedene Tierarzneimittel in Fleisch und von Fungiziden und Pestiziden in pflanzlichen Lebensmitteln zu nennen (Tabelle 2). Insbesondere in der Pestizidanalytik werden routinemäßig isotopenmarkierte Standards eingesetzt. Trotz größter kommerzieller Verfügbarkeit von markierten Substanzen aus diesem Bereich müssen bei der Vielzahl von Analyten meist mehrere Verbindungen auf einen isotopenmarkierten Standard bezogen werden. Die beispielhaft aufgeführte Arbeit (Tabelle 2) bestimmt 89 Analyten mit 14 stabilisotopenmarkierten Standards (Ueno et al. 2004).

Auch für die Analytik von Kontaminanten werden mehr und mehr SIVAs entwickelt. Dazu gehören sowohl klassische Kontaminanten wie Kunststoffadditive, Farbstoffe, polyzyklische aromatische Kohlenwasserstoffe (PAKs), Dioxine und polychlorierte Biphenyle (PCBs), als auch toxische Substanzen, die erst bei der Zubereitung von Lebensmitteln entstehen, so zum Beispiel Acrylamid, heterozyklische aromatische Amine oder kanzerogene Produkte aus der Maillard-Reaktion (Tabelle 2). Auch Mykotoxine, die giftigen sekundären Stoffwechselprodukte von Schimmelpilzen, fallen in diese Gruppe. Aufgrund der in der Regel sehr komplexen Strukturen dieser Verbindungen wurden bisher nur für einige wenige Vertreter aus den etwa 
Tabelle 2 Beispiele für Stabilisotopenverdünnungsanalysen von organischen Spurenkomponenten in Lebensmitteln

\begin{tabular}{|c|c|c|c|c|}
\hline & Lebensmittel & Analyt(en) & Standard(s) & Literatur \\
\hline \multicolumn{5}{|c|}{ Qualitätsgebende Inhaltstoffe von Lebensmitteln: } \\
\hline \multirow[t]{6}{*}{ Vitamine } & Speiseöl & $\alpha$-Tocopherol & {$\left[{ }^{2} \mathrm{H}\right]_{13}-\alpha$-Tocopherol } & Thomas et al. 1981 \\
\hline & Milch & Pyridoxol, Vitamin $\mathrm{B}_{6}$ & {$\left[{ }^{2} \mathrm{H}\right]_{5}$-Pyridoxol } & Hachey et al. 1985 \\
\hline & Milch & Vitamin C & {$\left[{ }^{13} \mathrm{C}\right] 6$-Vitamin $\mathrm{C}$} & Ellerbe et al. 1988 \\
\hline & Milchpulver, Reis, Apfelsaft & Pantothensäure & {$\left[{ }^{13} \mathrm{C}_{3},{ }^{15} \mathrm{~N}\right]$-Pantothensäure } & Rychlik 2000 \\
\hline & $\begin{array}{l}\text { Gemüse, Muskelfleisch, } \\
\text { Getreide, Orangensaft }\end{array}$ & Folate & {$\left[{ }^{2} \mathrm{H}_{4}\right]$-Analoga } & Freisleben et al. 2003 \\
\hline & Milch & Niacin & {$\left[{ }^{2} \mathrm{H}_{4}\right]$-Nikotinsäure } & Goldschmidt und Wolf 2007 \\
\hline \multirow[t]{4}{*}{ Aromastoffe (Auswahl) } & Brot & 2-Acetylpyrrolin & {$\left[{ }^{2} \mathrm{H}\right]_{2-5}$-2-Acetylpyrrolin } & Schieberle und Grosch 1987 \\
\hline & Honig, Kaffee, Tee, Bier & $\beta$-Damascenon & {$\left[{ }^{2} \mathrm{H}\right]$-Analoges } & Sen et al. 1991 \\
\hline & Haselnüsse & $\begin{array}{l}\text { 5-Methyl-(E)-2-hepten-4-on } \\
\text { (Filberton) }\end{array}$ & {$\left[{ }^{2} \mathrm{H}\right]_{2}$-Filberton } & Pfnür et al. 1999 \\
\hline & Trauben, Rotwein & $\beta$-Ionon & {$\left[{ }^{2} \mathrm{H}\right]_{3}-\beta$-Ionon } & Kotseridis et al. 1999a \\
\hline Geschmacksstoffe & Kaffee, Kakao & $\begin{array}{l}\text { N-Phenylpropenoyl-L-Amino- } \\
\text { säuren }\end{array}$ & {$\left[{ }^{2} \mathrm{H}\right]$-Analoga } & Stark et al. 2006 \\
\hline \multicolumn{5}{|l|}{ Rückstände: } \\
\hline \multirow[t]{6}{*}{ Tierarzneimittel } & Muskelfleisch & Ipronidazol & {$\left[{ }^{2} \mathrm{H}\right]_{3}$-Ipronidazol } & Garland et al. 1980 \\
\hline & Muskelfleisch & Sulfonamide & {$\left[{ }^{13} \mathrm{C}\right]_{4^{-}{ }^{-}}$-Analoge } & Simpson et al. 1985 \\
\hline & Muskelfleisch & Diethylstilböstrol & {$\left[{ }^{2} \mathrm{H}\right]_{4}$ - Diethylstilböstrol } & Covey et al. 1985 \\
\hline & Muskelfleisch & Benzylpenicillin & {$\left[{ }^{13} \mathrm{C}\right]_{2}$-Benzylpenicillin } & Schlösser et al. 1998 \\
\hline & Milchpulver & Chloramphenicol & {$\left[{ }^{2} \mathrm{H}\right]_{5}$-Chloramphenicol } & Guy et al. 2004 \\
\hline & Eier, Fleisch & Nitroimidazol-Derivate & {$\left[{ }^{2} \mathrm{H}\right]_{3}$-Analoga } & Mottier et al. 2006 \\
\hline Fungizide & Pflanzliche Lebensmittel & Dithiocarbamate & {$\left[{ }^{2} \mathrm{H}\right]$-Analoge } & Crnogorac und Schwack 2007 \\
\hline Pestizide (Beispiel) & Pflanzliche Lebensmittel & 89 Pestizide & $14\left[{ }^{2} \mathrm{H}\right]-$ bzw. $\left[{ }^{13} \mathrm{C}\right]$-Analoge & Ueno et al. 2004 \\
\hline \multicolumn{5}{|l|}{ Kontaminanten: } \\
\hline \multirow[t]{4}{*}{ Kunststoffaddiditve } & Fetthaltige Lebensmittel & Phthalate, Citrate & {$\left[{ }^{2} \mathrm{H}\right]_{4}$-Analoge } & Castle et al. 1988 \\
\hline & Käse, Fleisch, Fisch, Kuchen & Di-(2-ethylhexyl)-Adipat (DEHA) & {$[2 \mathrm{H} 4]-\mathrm{DEHA}$} & Startin et al. 1987 \\
\hline & Babynahrung, Fruchtsäfte & 2-Ethyl-Hexansäure & {$\left[{ }^{2} \mathrm{H}\right]_{15}-2$ Ethyl-Hexansäure } & Ellendt et al. 2005 \\
\hline & Babynahrung, Pesto & $\begin{array}{l}\text { Epoxidiertes Soyabohnenöl } \\
\text { (ESBO) }\end{array}$ & {$\left[{ }^{13} \mathrm{C}\right]_{18}$-ESBO } & Rothenbacher und Schwack 2007 \\
\hline \multirow[t]{3}{*}{ Acrylamid } & Kekse, Brot, Oblaten, Nüsse & Acrylamid & {$\left[{ }^{13} \mathrm{C}\right]_{3}$-Acrylamid } & Riediker und Stadler 2003 \\
\hline & Kartoffelchips, Butterkekse & Acrylamid & {$\left[{ }^{13} \mathrm{C}\right]_{3}$-Acrylamid } & Jezussek und Schieberle 2003 \\
\hline & Kaffee, Kakao & Acrylamid & {$\left[{ }^{13} \mathrm{C}\right]_{3}$-Acrylamid } & Aguas et al. 2006 \\
\hline Azofarbstoffe & $\begin{array}{l}\text { Chilipulver, Wurst, Toma- } \\
\text { tensauce }\end{array}$ & $\begin{array}{l}\text { Sudan I, II, III, IV, Sudan Para- } \\
\text { Red }\end{array}$ & {$\left[{ }^{2} \mathrm{H}\right]_{6}$-Analoga } & Mazzotti et al. 2008 \\
\hline Dioxine und PCBs & Fleisch, Fisch, Milch & $\begin{array}{l}\text { Polychlorierte Dibenzo-p- } \\
\text { Dioxane, Dibenzo-Furane und } \\
\text { Biphenyle }\end{array}$ & {$\left[{ }^{13} \mathrm{C}\right]$-Analoge } & Focant et al. 2005 \\
\hline Flammschutzmittel & Fleisch, Ö1 & Polybromierte Diphenylether & {$\left[{ }^{13} \mathrm{C}\right]_{12}$-Analoge } & Gomara et al. 2005 \\
\hline $\begin{array}{l}\text { Polyzyklische aromatische } \\
\text { Kohlenwasserstoffe (PAK) }\end{array}$ & $\begin{array}{l}\text { Geräucherte Lebensmittel, } \\
\text { Öl }\end{array}$ & 19 PAKs & {$\left[{ }^{13} \mathrm{C}\right]$-Analoge } & Veyrand et al. 2007 \\
\hline \multirow[t]{2}{*}{$\begin{array}{l}\text { Kanzerogene aus der } \\
\text { Maillard-Reaktion }\end{array}$} & $\begin{array}{l}\text { Kaffee, Bier, Malz, Kakao, } \\
\text { Kartoffelchips }\end{array}$ & $\begin{array}{l}\text { Di- und Trihydroxy-Benzol- } \\
\text { Derivate }\end{array}$ & {$[2 \mathrm{H}]$-Analoge } & Lang et al. 2006 \\
\hline & Fleisch & Heterozyklische Amine & {$\left[{ }^{2} \mathrm{H}\right]_{3}$-Analoge } & Yamaizumi et al. 1986 \\
\hline \multirow[t]{7}{*}{ Mykotoxine (Auswahl) } & Mais & Fumonisin $\mathrm{B}_{1}$ & {$\left[{ }^{2} \mathrm{H}\right]_{3}$-Fumonisin $\mathrm{B}_{1}$} & Hartl und Humpf 1999 \\
\hline & Apfelsaft & Patulin (PAT) & {$\left[{ }^{13} \mathrm{C}\right]_{2}$-PAT } & Rychlik und Schieberle 1999 \\
\hline & $\begin{array}{l}\text { Kaffee, Wein, Gewürze, } \\
\text { Rosinen }\end{array}$ & Ochratoxin A (OTA) & {$\left[{ }^{2} \mathrm{H}\right]_{5}-\mathrm{OTA}$} & Lindenmeier et al. 2004 \\
\hline & Weizen, Mais & Deoxynivalenol & {$\left[{ }^{13} \mathrm{C}\right]_{15}-\mathrm{DON}$} & Häubl et al. 2006 \\
\hline & Haferflocken & T2-Toxin, HT2-Toxin & {$\left[{ }^{13} \mathrm{C}\right]$-Analoga } & Asam und Rychlik 2006 \\
\hline & Cornflakes, Tortilla-Chips & Zearalenon (ZEA) & {$\left[{ }^{2} \mathrm{H}\right]_{2}$-ZEA } & Cramer et al. 2007 \\
\hline & Nüsse, Mais, Gewürze & Aflatoxin (AF) $B_{1}, B_{2}, G_{1}, G_{2}$ & {$\left[{ }^{2} \mathrm{H}\right]_{2}-\mathrm{AF}-\mathrm{B}_{2} ;\left[{ }^{2} \mathrm{H}\right]_{2-4}-\mathrm{AF}-\mathrm{G}_{2}$} & Cervino et al. 2008 \\
\hline \multicolumn{5}{|c|}{ Natürliche Minorkomponenten: } \\
\hline & Leinsamen & Lignane & {$\left[{ }^{2} \mathrm{H}\right]_{4}$ bzw. $\left[{ }^{2} \mathrm{H}\right]_{6}$-Analoge } & Mazur et al. 1996 \\
\hline & Ferulasäure, Kaffeesäure & Hafer & {$\left[{ }^{13} \mathrm{C}\right]-$ Analoga } & Guth und Grosch 1994 \\
\hline & Dityrosin & Weizen & {$\left[{ }^{13} \mathrm{C}\right]_{2}$-Dityrosin } & Hanft und Köhler 2005 \\
\hline
\end{tabular}


300-400 bekannten Mykotoxinen SIVAs entwickelt. Einige Beispiele sind in Tabelle 2 aufgeführt. Ein ausführlicher Überblick über den Einsatz von SIVAs bei der Analytik von Mykotoxinen wurde vor kurzem publiziert (Rychlik und Asam 2008).

\section{Schlussfolgerungen und Ausblick}

Die Kompensation von Verlusten während der Probenvorbereitung sowie von Ionisationsunterdrückungen bei der Massenspektrometrie sind neben verbesserter Spezifität die wesentlichen Vorzüge der SIVA in der Spurenanalytik. Immer mehr der dafür erforderlichen isotopologen Standards werden kommerziell verfügbar oder sind durch bekannte Synthesewege herstellbar. Mit geeigneten Standards ist Kalibrierung und Auswertung der Ergebnisse problemlos möglich. Die wachsende Akzeptanz dieser Methode, vor allem im Bereich der Anwender der LC-MS, spiegelt sich in einer Vielzahl von Einsatzbereichen auch in der Lebensmittelanalytik wieder. Damit ist die IVA trotz ihrer fast hundertjährigen Geschichte aktueller denn je und wird auch in Zukunft ein wichtiges Instrument im Zusammenspiel der spurenanalytischen Methoden bleiben.

\section{Literatur}

Aguas PC, Fitzhenry MJ, Giannikopoulos G, Varelis P (2006) Analysis of acrylamide in coffee and cocoa by isotope dilution liquid chromatography-tandem mass spectrometry. Anal Bioanal Chem 385(8):1526-1531

Asam S, Rychlik M (2006) Synthesis of four carbon-13-labeled type a trichothecene mycotoxins and their application as internal standards in stable isotope dilution assays. J Agric Food Chem 54(18):6535-6546

Aston FW (1919) Neon. Nature 104:334

Blom KF (1987) Average mass approach to stable isotope dilution mass spectrometry. Org Mass Spectrom 22:530-533

Boni RL, Simpson JT, Naritsin DB, Saito K, Markey SP (1994) Quantification of L-tryptophan and L-kynurenine by liquid chromatography/electron capture negative ion chemical ionization mass spectrometry. Biol Mass Spectrom 23:27-32

Bretz M, Beyer M, Cramer B, Humpf H-U (2006) Stable isotope dilution analysis of the Fusarium mycotoxins deoxynivalenol and 3-acetyldeoxynivalenol. Mol Nutr Food Res 50:251-260

Brown TJ, Kline MC, Gill LM, Yen JH, Duewer DL, Sniegoski LT, Sharpless KE (2001) Preparation and value assignment of Standard Reference Material 968c Fat-soluble vitamins, carotenoids, and cholesterol in human serum. Clin Chim Acta 305:141-155

Bush ED, Trager WF (1981) Analysis of linear approaches to quantitative stable isotope methodology in mass spectrometry. Biomed Mass Spectrom 8:211-218

Castle L, Mercer AJ, Startin JR, Gilbert J (1988) Migration from plasticized films into foods. 3. Migration of phthalate, sebacate, citrate and phosphate esters from films used for retail food packaging. Food Addit Contam 5(1):9-20

Cervino C, Asam S, Knopp D, Rychlik M, Niessner R (2008) Use of isotope-labeled aflatoxins for LC-MS/MS stable isotope dilution analysis of foods. J Agric Food Chem 56(6):1873-1879
Cohen A, Hertz HS, Mandel J, Paule RC, Schaffer R, Sniegoski LT, Sun T, Welch MJ, White EV (1980) Total serum cholesterol by isotope dilution/mass spectrometry: a candidate definitive method. Clin Chem 26:854-60

Colby BN, McCaman MW (1979) A comparison of calculation procedures for isotope dilution determinations using gas chromatography mass spectrometry. Biomed Mass Spectrom 6:225-230

Covey T, Maylin G, Henion J (1985) Quantitative secondary ion monitoring gas chromatography/mass spectrometry of diethylstilbestrol in bovine liver. Biomed Mass Spectrom 12(6):274-87

Cramer B, Bretz M, Humpf H-U (2007) Stable isotope dilution analysis of the Fusarium mycotoxin zearalenone. J Agric Food Chem 55(21):8353-8358

Crnogorac G, Schwack W (2007) Determination of dithiocarbamate fungicide residues by liquid chromatography/mass spectrometry and stable isotope dilution assay. Rapid Comm Mass Spectrom 21(24):4009-4016

Dueker SR, Jones AD, Smith GM, Clifford AJ (1994) Stable isotope methods for the study of b-carotene-d8 metabolism in humans utilizing tandem mass spectrometry and high-performance liquid chromatography. 66:4177-4185

Ellendt K, Weisshaar R, Baumann M (2005) Determination of 2-ethylhexanoic acid in baby food and fruit juices packaged in glass jars by isotope-dilution gas chromatography. D Lebensm Rundsch 101(11):493-497

Ellerbe P, Sniegoski LT, Miller JM, White EV (1988) An isotope dilution mass spectrometric (IDMS) method for the determination of vitamin C in milk. Journal of Research of the National Bureau of Standards (United States) 93(3):367 f.

Fay LB, Metairon S, Baumgartner M (2001) Linearization of secondorder calibration curves in stable isotope dilution-mass spectrometry. Flavour Frag J 16:164-168

Focant J-F, Eppe G, Scippo M-L, Massart A-C, Pirard C, MaghuinRogister G, De Pauw E (2005) Comprehensive two-dimensional gas chromatography with isotope dilution time-of-flight mass spectrometry for the measurement of dioxins and polychlorinated biphenyls in foodstuffs. J Chromatogr A 1086 (1-2):45-60

Freisleben A, Schieberle P, Rychlik M (2003) Specific and sensitive quantification of folate vitamers in foods by stable isotope dilution assays using high-performance liquid chromatography-tandem mass spectrometry. Anal Bioanal Chem 376:149-156

Garland WA, Hodshon BJ, Chen G, Weiss G, Felicito NR, MacDonald A (1980) Determination of ipronidazole and its principal metabolite in turkey skin and muscle by combined gas chromatography-negative chemical ionization mass spectrometry-stable isotope dilution. J Agric Food Chem 28(2):273-277

Goldschmidt RJ, Wolf WR (2007) Determination of niacin in food materials by liquid chromatography using isotope dilution mass spectrometry. J AOAC Int 90:1084-1089

Gomara B, Herrero L, Bordajandi LR, Gonzalez MJ (2005) Quantitative analysis of polybrominated diphenyl ethers in adipose tissue, human serum and foodstuff samples by gas chromatography with ion trap tandem mass spectrometry and isotope dilution. Rapid Comm Mass Spectrom 20(2):69-74

Guth H, Grosch W (1994) Quantitative analysis of caffeic and ferulic acids in oatmeal. Comparison of a conventional method with a stable isotope dilution assay. Z Lebensm Unters Forsch 199(3): 195-197

Guy PA, Royer D, Mottier P, Gremaud E, Perisset A, Stadler RH (2004) Quantitative determination of chloramphenicol in milk powders by isotope dilution liquid chromatography coupled to tandem mass spectrometry. J Chromatogr A 1054(1-2):365371

Hachey DL, Coburn SP, Brown LT, Erbelding WF, Demark B, Klein PD (1985) Quantitation of vitamin B6 in biological samples by isotope dilution mass spectrometry. Anal Biochem 151:159-168 
Häubl G, Berthiller F, Krska R, Schuhmacher R (2006) Suitability of a fully $13 \mathrm{C}$ isotope labeled internal standard for the determination of the mycotoxin deoxynivalenol by LC-MS/MS without clean up. Anal Bioanal Chem 384(3):692-696

Hanft F, Köhler P (2005) Quantitation of dityrosine in wheat flour and dough by liquid chromatography-tandem mass spectrometry. J Agric Food Chem 53(7):2418-2423

Hartl M, Humpf H-U (1999) Simultaneous Determination of Fumonisin B1 and Hydrolyzed Fumonisin B1 in Corn Products by Liquid Chromatography/Electrospray Ionization Mass Spectrometry. J Agric Food Chem 47(12):5078-5083

Haskins NJ, Ford GC, Grigson SJW, Waddell KA (1978) A carrier effect observed in assays for antidiarrheal drug compounds. Biomed Mass Spectrom 5:423-424

Heumann KG (1986) Isotope dilution mass spectrometry of inorganic and organic substances. Fresenius J Anal Chem 325:661-666

Hevesy G, Jacobsen CF (1940) Rate of passage of water through capillary and cell walls. Acta Physiol Scand 1:11-18

Hevesy G, Paneth F (1913) The solubility of lead sulfide and lead chromate. Z Anorg Chem 82:323-328

Holmes JC, Morell FA (1957) Oscillographic mass spectrometry monitoring of gas chromatography. Appl Spectrosc 11:86-87

Horwitz W, Kamps LR, Boyer KW (1980) Quality Assurance in the analysis of foods for trace constituents. J AOAC Int 63:1344

Jessome LL, Volmer DA (2006) Ion suppression: a major concern in mass spectrometry. LCGC North America (Suppl.):83-89

Jezussek M, Schieberle P (2003) A new LC/MS-method for the quantitation of acrylamide based on a stable isotope dilution assay and derivatization with 2 -mercaptobenzoic acid. comparison with two GC/MS methods. J Agric Food Chem 51(27):7866-7871

Jonckheere JA, Leenheer APD (1983) Statistical evaluation of calibration nonlinearity in isotope dilution gas chromatography/mass spectrometry. Anal Chem 55:153-155

Kotseridis Y, Baumes RL, Bertrand A, Skouroumounis GK (1999a) Quantitative determination of $\beta$-ionone in red wines and grapes of bordeaux using a stable isotope dilution assay. J Chromatogr A $848(1-2): 317-325$

Kotseridis Y, Baumes RL, Skouroumounis GK (1999b) Quantitative determination of free and hydrolytically liberated $\beta$-damascenone in red grapes and wines using a stable isotope dilution assay. J Chromatogr A 849:245-254

Lang R, Mueller C, Hofmann T (2006) Development of a stable isotope dilution analysis with liquid chromatography-tandem mass spectrometry detection for the quantitative analysis of di- and trihydroxybenzenes in foods and model systems. J Agric Food Chem 54(16):5755-5762

Lindenmeier M, Schieberle P, Rychlik M (2004) Quantification of ochratoxin $\mathrm{A}$ in foods by a stable isotope dilution assay using high-performance liquid chromatography-tandem mass spectrometry. J Chromatogr A 1023(1):57-66

Mazur W, Fotsis T, Wahala K, Ojala S, Salakka A, Adlercreutz H (1996) Isotope dilution gas chromatographic-mass spectrometric method for the determination of isoflavonoids, coumestrol, and lignans in food samples. Anal Biochem 233(2):169-180

Mazzotti F, Di Donna L, Maiuolo L, Napoli A, Salerno R, Sajjad A, Sindona G (2008) Assay of the set of all sudan azodye (I, II, III, IV, and para-red) contaminating agents by liquid chromatography-tandem mass spectrometry and isotope dilution methodology. J Agric Food Chem 56(1):63-67

Mottier P, Hure I, Gremaud E, Guy PA (2006) Analysis of four 5-nitroimidazoles and their corresponding hydroxylated metabolites in egg, processed egg, and chicken meat by isotope dilution liquid chromatography tandem mass spectrometry. J Agric Food Chem 54(6):2018-2026
Paneth F, Hevesy G (1914) Attempts to separate radium D from lead. Ueber Versuche zur Trennung des Radium D von Blei. Monatsh Chem 34:1393-1400

Papadakis I, Taylor PDP (2000) Establishment of SI-traceable reference ranges for the content of various elements in the IMEP-9 water sample. Accred Qual Assur 5:331-338

Pfnür P, Matsui T, Grosch W, Guth H, Hofmann T, Schieberle P (1999) Development of a Stable Isotope Dilution Assay for the Quantification of 5-Methyl-(E)-2-hepten-4-one: Application to Hazelnut Oils and Hazelnuts. J Agric Food Chem 47(5):2044-2047

Price KR (1979) A comparison of two quantitative mass spectrometric methods for the analysis of patulin in apple juice. Biomed Mass Spectrom 6:573-574

Quinn TJ (1997) Primary methods. Metrologia 34:61

Rasku S, Wähälä K, Koskimies J, Hase T (1999) Synthesis of isoflavonoid deuterium labeled polyphenolic phytoestrogens. Tetrahedron 55:3445-3454

Riediker S, Stadler RH (2003) Analysis of acrylamide in food by isotope-dilution liquid chromatography coupled with electrospray ionization tandem mass spectrometry. J Chromatogr A 1020(1):121-130

Rittenberg D, Foster GL (1940) A new procedure for quantitative analysis by isotope dilution with application to the determination of amino acids and fat acids. J Biol Chem 133:737-744

Rothenbacher T, Schwack W (2007) Determination of epoxidized soybean oil by gas chromatography/single quadrupole and tandem mass spectrometry stable isotope dilution assay. Rapid Comm Mass Spectrom 21(12):1937-1943

Rychlik M (2000) Quantification of free and bound pantothenic acid in foods and blood plasma by a stable isotope dilution assay. J Agric Food Chem 48:1175-1181

Rychlik M, Asam S (2008) Stable isotope dilution assays in mycotoxin analysis. Anal Bioanal Chem 390(2):617-628

Rychlik M, Schieberle P (1999) Quantification of the mycotoxin patulin by a stable isotope dilution assay. J Agric Food Chem 47(9):3749-3755

Sabot JF, Ribon B, Kouadio-Kouakou LP, Pinatel H, Mallein R (1988) Comparison of two calculation procedures for gas chromatography-mass spectrometry associated with stable isotope dilution. Analyst 113:1843-1847

Schieberle P, Grosch W (1987) Quantitative analysis of aroma compounds in wheat and rye bread crusts using a stable isotope dilution assay. J Agric Food Chem 35(2):252-257

Schloesser J, Mehlich A, Ballwanz F, Petz M (1998) Preparation of doubly 13C-labeled benzylpenicillin as internal standard for residue analytical use with GC/MS and LC/MS. Fresenius J Anal Chem 360(3-4):498-501

Sen A, Laskawy G, Schieberle P, Grosch W (1991) Quantitative determination of $\beta$-damascenone in foods using a stable isotope dilution assay. J Agric Food Chem 39(4):757-759

Simpson RM, Suhre FB, Shafer JW (1985) Quantitative gas chromatographic-mass spectrometric assay of five sulfonamide residues in animal tissue. J AOAC Int 68(1):23-26

Soddy F (1913) Intra-atomic charge. Nature 92:399-400

Staempfli AA, Blank I, Fumeaux R, Fay LB (1994) Study on the decomposition of the Amadori compound N-(1-deoxy-D-fructos-1-yl)glycine in model systems: quantification by fast atom bombardment tandem mass spectrometry. Biol Mass Spectrom 23:642-646

Stark T, Justus H, Hofmann T (2006) Quantitative analysis of n-phenylpropenoyl-1-amino acids in roasted coffee and cocoa powder by means of a stable isotope dilution assay. J Agric Food Chem 54(8):2859-2867

Startin JR, Parker I, Sharman M, Gilbert J (1987) Analysis of di(2-ethylhexyl)adipate plasticizer in foods by stable isotope dilution gas chromatography-mass spectrometry. J Chromatogr 387:509-514 
Streitwieser A, Heathcock CH (1980) Organische Chemie, Verlag Chemie, Weinheim, S. 326

Sweeley CC, Elliott WH, Fries I, Ryhage R (1966) Mass spectrometric determination of unresolved components in gas chromatographic effluents. Anal Chem 38:1549-1553

Thomas DW, Parkhurst RM, Negi DS, Lunan KD, Wen AC, Brandt AE, Stephens RJ (1981) Improved assay for $\alpha$-tocopherol in the picogram range, using gas chromatography-mass spectrometry. J Chromatogr 225(2):433-439

Ueno E, Oshima H, Saito I, Matsumoto H, Yoshimura Y, Nakazawa H (2004) Multiresidue analysis of pesticides in vegetables and fruits by gas chromatography/mass spectrometry after gel permeation chromatography and graphitized carbon column cleanup. J AOAC Int 87(4):1003-1015
Veyrand B, Brosseaud A, Sarcher L, Varlet V, Monteau F, Marchand P, Andre F, Le Bizec B (2007) Innovative method for determination of 19 polycyclic aromatic hydrocarbons in food and oil samples using gas chromatography coupled to tandem mass spectrometry based on an isotope dilution approach. J Chromatogr A 1149(2):333-344

Webb KS, Carter D (1997) The role of isotope dilution mass spectrometry in the development of tandem mass spectrometry for quantitative organic analysis. Rapid Comm Mass Spectrom $11: 155-158$

Yamaizumi Z, Kasai H, Nishimura S, Edmonds CG, McCloskey JA (1986) Stable isotope dilution quantification of mutagens in cooked foods by combined liquid chromatography-thermospray mass spectrometry. Mut Res Lett 173(1):1-7 